Cómo citar este trabajo: Descamps, G., \& Camprubí, R. (2018). 35 años de carteles turísticos en Cataluña: evolución de la imagen turística catalana del 1980 al 2015. Boletín de la Asociación de Geógrafos Españoles, 79, 2486, 1-25. http://dx.doi.org/10.21138/bage.2486

\title{
35 años de carteles turísticos en Cataluña: evolución de la imagen turística catalana del 1980 al 2015
}

\author{
35 years of tourist posters in Catalonia: \\ Gemma Descamps \\ gemma.descamps@gmail.com \\ Raquel Camprubí \\ raquel.camprubi@udg.edu \\ Facultad de Turismo \\ Universidad de Girona (España)
} evolution of the Catalan tourist image (1980-2015)

\section{Resumen}

Este artículo analiza la imagen turística de Cataluña a través de los carteles turísticos que se han publicado desde el año 1980 hasta la actualidad, con el fin de determinar los cambios producidos en las características y atributos promocionados del destino desde un punto de vista cronológico. Para ello se han analizado un total de 192 carteles mediante análisis de contenido. Los resultados apuntan una clara evolución de la imagen turística de Cataluña a lo largo del tiempo, con cambios substanciales en cada una de las etapas considerando los distintos factores analizados.

Palabras clave: carteles turísticos; Cataluña; imagen turística; análisis de contenido.

\section{Abstract}

This article analyses the tourism image of Catalonia through tourist posters published. It aims to analyse to what extent the characteristics and attributes promoted have changed over time, and also to examine whether structural changes of destination marketing organisations have had any influence 
over this evolution. In the study, a content analysis was carried out on a total of 192 posters. Results point out a clear evolution of the tourism image of Catalonia over time, with substantial changes at each stage, considering the various analysed factors.

Key words: tourist posters; Catalonia; tourist image; content analysis.

\section{Introducción}

La elección de un determinado destino está condicionada por múltiples factores que influyen en la persona y actúan como filtros para determinar su decisión (Gartner, 1994). Entre estos factores, la percepción o las impresiones, tanto positivas como negativas, que un destino cause sobre el usuario juegan un papel muy importante en su decisión final. Asimismo, la comunicación de estas impresiones en colectivos sociales, incide directamente en el reconocimiento y la competitividad de los destinos (Morgan \& Pritchard, 1998).

Así pues, la imagen turística de un destino, definida como un conjunto de creencias, ideas e impresiones que una persona tiene sobre un lugar determinado (Crompton, 1979; Kotler, Haider \& Rein, 1993), se tiene que entender como un elemento esencial para mejorar, mantener o modificar las percepciones que los turistas tienen de un determinado destino. Es decir, distintos agentes o eventos influyen en la creación de la imagen turística realzando determinados atributos o creencias asociadas al destino (Gartner, 1994).

Distintos autores exponen el importante papel que juega la imagen turística en los destinos para el proceso de selección del viaje turístico (Bigné, Sánchez, \& Sanz, 2009; Tasci \& Gartner, 2007; Um \& Crompton, 1999). Así mismo, otros autores analizan los elementos que influyen en la formación de la imagen turística (Baloglu \& McClearly, 1999; Beerli \& Martín, 2004), y los agentes que intervienen en este proceso (Gartner, 1994). En este tipo de investigaciones es frecuente el uso de folletos, catálogos turísticos o revistas de viajes, para determinar a través de las fotografías y textos la imagen turística que se proyecta del destino en cuestión (Dilley, 1986; Galí \& Donaire, 2005; Pritchard \& Morgan, 1995; Pritchard \& Morgan, 1996), permitiendo al mismo tiempo realizar un estudio cronológico.

Con esta misma idea, la presente investigación se centra en el cartel turístico como una herramienta de comunicación representativa de la imagen que proyectan los destinos, y que por tanto perciben los turistas potenciales. Al mismo tiempo, a lo largo de la historia, los carteles se han postulado como una herramienta indispensable en el sector turístico para la promoción de los destinos. Aunque hoy en día el uso de carteles entre las técnicas de comunicación haya disminuido, por sus valores históricos y artísticos siguen siendo estudiados, teniendo un papel privilegiado en el ámbito de la comunicación turística (Civit \& Boada, 2003). Algunos ejemplos son el estudio sobre el cartelismo de las comarcas gerundenses Imatge i Destí: Cartells turístics de les comarques de 
Girona (Vidal \& Monturiol, 2003) y el Catálogo de Carteles oficiales de Turismo: 1929-1959 (Centro de Documentación Turística de España, 2005).

En este contexto, el objetivo del presente artículo consiste en analizar la imagen turística de un destino a través de los carteles turísticos desde una perspectiva cronológica, para poder determinar si las características y atributos promocionados del destino han cambiado a lo largo del tiempo, o por el contrario siguen las mismas pautas. Al mismo tiempo, se analizará si los cambios estructurales en el ente de promoción del destino tienen algún tipo de influencia en dicha evolución.

El presente artículo se estructura a partir de cuatro apartados. En primer lugar, se presenta el marco teórico dónde se hace especial referencia al papel del cartel turístico como generador de la imagen turística. En segundo lugar, se presenta el desarrollo metodológico en el cuál se toma como caso de estudio los carteles turísticos publicados en Cataluña entre los años 1980 y 2015. En tercer lugar, se presentan los principales resultados considerando, entre otros elementos, el año de publicación y la distribución geográfica de los lugares que aparecen en los carteles. Finalmente, se presentan las conclusiones con una discusión sobre el tema analizado y algunas líneas para futuras investigaciones.

\section{Revisión de la literatura}

\subsection{Entidades de promoción del destino y su papel en la generación de la imagen turística}

Los destinos son considerados emplazamientos geográficos que atraen determinados visitantes, durante un periodo de tiempo concreto, para que participen en las actividades turísticas del mismo, convirtiéndose así, en centros turísticos (Pike, 2004). En este sentido, los destinos turísticos, como estructuras organizativas complejas donde múltiples y diversos agentes interactúan entre ellos con el propósito de emitir una atractiva experiencia turística (Camprubí, Guia \& Comas, 2014), se convierten en áreas con características reconocidas por los visitantes potenciales y formadas por diversos recursos turísticos, tanto primarios (clima, patrimonio arquitectónico, paisaje...) como secundarios (hoteles, restaurantes, actividades de ocio...), que contribuyen a crear un producto turístico satisfactorio (Laws, 1995).

Sin embargo, la gestión del turismo en los destinos necesita de un ente de promoción que lleve a cabo acciones de comunicación eficientes para posicionarlos en el imaginario colectivo de los turistas potenciales. De esta necesidad aparecen las entidades de promoción del destino, que responden a cualquier tipo de organización con interés en el desarrollo de la actividad turística de un territorio concreto y encargada de llevar a cabo las acciones de marketing del mismo (Pike, 2004), siendo sus principales funciones actuar como responsables de la promoción de un territorio, asesorar sobre las políticas gubernamentales del mismo y dar apoyo a la actividad que desarrollan las empresas privadas del sector turístico. 
En particular, en la formación de la imagen turística de un territorio, si bien la entidad de promoción del mismo tiene un papel muy relevante, no es el único agente que interviene en este proceso, sino que los agentes que participan en la actividad turística de los destinos también juegan un papel muy destacado. En este contexto, Gartner (1994) argumenta la existencia de varios tipos de agentes que de forma voluntaria o involuntaria intervienen en el proceso de formación de la imagen turística del destino, proyectando ideas, creencias y conocimientos sobre éste.

Así pues, hay que considerar que la imagen en la que invierten las entidades de gestión turística de los destinos puede ser alterada por numerosos factores y agentes, dado que esta se modifica en cada una de las fases que conlleva la toma de decisión del viaje turístico (Gunn, 1972). Por tanto, el principal objetivo de los entes de promoción del destino ha de ser el de crear una imagen positiva de éste que sea transmitida en el momento de elegir el viaje y satisfacer las necesidades de los visitantes durante su estancia, maximizando así su experiencia turística y promoviendo una realidad positiva (Chon, 1991; Selby \& Morgan, 1996).

Consecuentemente, es de vital importancia que el ente de promoción del destino turístico sea capaz de generar una estrategia de creación de la imagen turística suficientemente consistente, para así poder transmitir los valores y atributos deseados (Govers \& Go, 2004). Además, debe liderar el proceso para poder minimizar los efectos negativos que puedan tener los mensajes que no se ajustan a la estrategia planeada y son propiciados por agentes exógenos al destino.

Este proceso implicará tener en consideración varios factores, entre ellos el presupuesto disponible, los segmentos de mercado deseados, el/los producto/s turístico/s ofrecido/s en el destino, la fortaleza de la imagen del destino, etc. (Gartner, 1994), que condicionarán el uso de las herramientas de comunicación más apropiadas según cada caso, entre las cuáles se encuentran los carteles turísticos.

\subsection{Carteles turísticos}

La intangibilidad de los productos y servicios turísticos hace que la expectativa de los usuarios hacia el viaje sólo se pueda corroborar tras adquirir y efectuar el mismo, por lo tanto, las únicas evidencias físicas que tienen los consumidores sobre el viaje que quieren comprar son los catálogos, las páginas web o los diferentes medios de comunicación utilizados para su promoción.

Los medios de comunicación tradicionales, basados mayormente en soporte papel, siempre han representado un factor muy importante en cuanto a la imagen de un destino turístico, teniendo una fuerte influencia en la decisión de los visitantes potenciales y dando credibilidad a lo que se quiere transmitir (Gomis, 2011).

Entre estos métodos, el cartel se ha desarrollado a lo largo de los años según diferentes técnicas y estilos artísticos, convirtiéndose en una herramienta de difusión muy influyente. Sus orígenes se 
remontan a mediados del siglo XIX, cuando el desarrollo del viaje turístico como potente industria económica obligó a las empresas a hacer uso de técnicas publicitarias (Weill, 2003). En Francia fue dónde a partir de la década de 1880 se desarrolló plenamente el cartelismo con Jules Chéret como máximo exponente (Monturiol, 2011). En este contexto, los carteles turísticos se convirtieron a lo largo del siglo XIX en un reflejo del deseo social de viajar, con el objetivo de hacer soñar al público con destinos que no habían visto nunca. En España la consolidación del cartel como medio de promoción alcanzó su esplendor durante el primer tercio del siglo XX (Fernández \& Valero, 2015).

Este medio de comunicación permite, a los entes de promoción de los destinos, transmitir la imagen turística deseada sobre el territorio en cuestión. Así pues, los carteles son utilizados por los destinos con la finalidad de captar la atención del público y crear la necesidad de viajar a aquel destino que sale representado, desarrollando su acción comunicativa a través del lenguaje visual (Weill, 2003).

Como técnica de promoción, el cartel se define como una unidad de comunicación, editada en soporte papel y formada por dos elementos principales (Fernández \& Valero, 2015): (a) la imagen, que representa la reproducción icónica del producto, y (b) el texto, que supone la explicación escrita del mismo.

En cuanto a su clasificación, se pueden diferenciar según la combinación de elementos que presentan (Alcocer, 1991); carteles compuestos por texto e imagen, aquellos que sólo tienen imagen, utilizados en casos donde el producto o servicio ya tiene un fuerte reconocimiento; y aquellos que sólo presentan texto, los cuales tienen una finalidad informativa. Su efectividad, sin embargo, está en la correcta combinación de los elementos que lo conforman de acuerdo con el mensaje que se quiere transmitir.

Cabe destacar que la imagen de los carteles tiene una gran relevancia, dado que su efectividad depende en gran parte del poder de atracción que esta demuestre (Coronado, 2001). La función informativa, sin embargo, es asumida por otros elementos, como el texto, el nombre de la marca, el eslogan, etc., debido a que la información que presenta la imagen a menudo es imprecisa y difícil de asociar; mientras que el texto tiene capacidad para enriquecer esta información y expresar las significaciones que se le quieran atribuir (Enel, 1977).

Durante los últimos años, la confianza en los carteles como medio de promoción turística ha quedado seriamente cuestionada ante otras herramientas de comunicación más actuales (publirreportaje, campañas de televisión, viajes de familiarización, páginas web, redes sociales, etc.). Además, en el marco de la actividad turística, son un elemento renovable, es decir, de naturaleza efímera, lo que, junto con su fragilidad, dimensiones y cambios en las estructuras y organismos de promoción que los editan, dificulta su conservación (Monturiol, 2011). Aunque los 
carteles turísticos comienzan a desempeñar una función subsidiaria (Civit \& Boada, 2003), hay que remarcar que, tanto en su vertiente promocional como artística, estos ayudan, a través de sus imágenes y textos, a comprender la evolución del turismo, lo que los convierte en elementos indispensables en el contexto de la promoción y difusión turística.

Las investigaciones sobre el cartel turístico, frecuentemente, se han concentrado en determinar los atributos promocionados de un determinado espacio geográfico (Fernández \& Valero, 2015; Blanchard, 2007; Young-Hoon, 2003; Pelta, 2011; Suchert \& Tuppen, 2009), o temático, tales como las actividades lúdicas (Debié, 1993) y deportivas (Guillain, 2006, 2007) representadas en los carteles; o bien los carteles propiciados por determinadas organizaciones turísticas, identificándose las compañías ferroviarias (Quendoz, 1991; Pégé-Defendi, 2003) cómo las más relevantes. Como estudio singular, se encuentra el publicado por Pécout, Bohuon y Birot (2010), el cual se centra en estudiar la representación de la mujer en los carteles turísticos de estaciones balnearias. El rasgo común en la mayoría de estos estudios se encuentra en la cronología estudiada, la cual coincide con el período de máximo esplendor del cartel publicitario, es decir, finales del siglo XIX y el primer tercio del siglo XX. Precisamente, el estudio de esta época conduce a que gran parte de estas investigaciones mencionen la autoría de los artistas que diseñaron los carteles como elemento relevante. Así pues, el análisis del cartel turístico se ha focalizado en su vertiente histórica, siendo una herramienta para reconstruir la historia del turismo y comprender su desarrollo. Por tanto, son casi inexistentes los estudios del cartel turístico más reciente. También cabe destacar que fácilmente se puede encontrar un mayor número de artículos referentes al territorio francés (Suchet \& Tuppen, 2009), sus colonias, como Marruecos (Blanchard, 2007) o de compañías ferroviarias (Pégé-Defendi, 2003). Este hecho va especialmente vinculado a la contribución de los artistas de este país en el desarrollo del cartel cómo herramienta de promoción. En referencia al estudio del cartel turístico español, se encuentran algunos artículos que se centran en analizar el papel del cartel turístico en la construcción de la identidad turística española (Fernández \& Valero, 2015) y la imagen de España (Pelta, 2011), siguiendo también la perspectiva histórica mencionada anteriormente.

A nivel metodológico, si bien se puede deducir que estos estudios se basan en un análisis de contenido de los carteles, estos aspectos técnicos no se especifican directamente. Este elemento va ligado al propósito de relato histórico de la mayoría de artículos, en los cuales se aporta un discurso fundamentalmente cualitativo (Blanchard, 2007; Ziolko, 2015), y en sólo pocos casos se aportan algunos datos estadísticos fruto del análisis realizado (Pégé-Defendi, 2003). 


\section{Metodología}

Con el objetivo de analizar la evolución de la imagen turística de Cataluña a través de los carteles turísticos, se han tomado como muestra 192 carteles editados por la Dirección General de Turismo, principal órgano gubernamental encargado de la gestión turística del territorio, y por los entes de promoción del destino.

Para el análisis de los carteles, se ha considerado dividir los 35 años del periodo de estudio en tres etapas, coincidiendo con el desarrollo de los distintos entes de promoción de Cataluña:

- De 1980 a 1985: coincidiendo con los primeros años de la recuperación de competencias en materia turística por parte de la Generalitat de Catalunya y, en consecuencia, de la creación del Departament de Comerç Consum i Turisme (DCCT).

- De 1986 a 2009: periodo que incluye la creación y desarrollo del Consorci de Promoció Turística de Catalunya, posteriormente denominado Turisme de Catalunya (TC).

- De 2010 a 2015: TC es sustituido por la actual Agència Catalana de Turisme (ACT), asumiendo todas sus tareas y funciones, e iniciándose una nueva etapa.

La recogida de datos se ha realizado mediante el análisis de contenido de los carteles turísticos incluidos en la muestra. El análisis de contenido es un método de investigación observacional que se utiliza sistemáticamente para evaluar el contenido simbólico de cualquier medio o forma de comunicación (Kolbe \& Burnett, 1991). La aplicación del método ha seguido los preceptos establecidos por Camprubí y Coromina (2016) con el fin de garantizar la objetividad, fiabilidad y reproducibilidad del mismo en otras investigaciones. Durante el proceso de análisis han intervenido dos investigadores, de modo que aquellos elementos que comportaban algún tipo de discrepancia han sido discutidos hasta llegar a un acuerdo común.

En particular, a partir de una extensa revisión de la literatura académica (Dilley, 1986; Galí \& Donaire, 2005; Pritchard \& Morgan, 1996; Jenkins, 2003; Choi, Letho \& Morrison, 2007; Camprubí, Guia \& Comas, 2014) se han definido cuatro categorías (paisaje, patrimonio, cultura y actividades turísticas), y nueve subcategorías (Tabla 1), permitiendo clasificar la imagen que aparece en cada cartel de forma sistemática. Además, para la clasificación de las imágenes en las diferentes categorías definidas se han considerado los "eye catchers" (Pritchard \& Morgan, 1995), consistiendo en categorizar los contenidos según la imagen que ocupa el 50 \% o más del documento y, en consecuencia, que se convierte en la dimensión principal del mismo.

Un elemento importante a tener en cuenta en el análisis de las imágenes es el nivel de humanización que presentan (Galí, 2005), dado que la presencia o no de personas condiciona el mensaje que se quiere transmitir. En este sentido, se han clasificado las imágenes según si hay o no presencia de 
personas, y en caso que hubiera personas, si estas son locales, turistas, locales y turistas o líderes de opinión. También se ha considerado el género de las personas presentes en los carteles.

Tabla 1. Descripción de las categorías y subcategorías de la imagen

\begin{tabular}{|c|c|c|}
\hline Categoría & Subcategoría & Definición \\
\hline \multirow{4}{*}{ Paisaje } & Costa & $\begin{array}{l}\text { Incluye aquellas imágenes que retratan elementos costeros y/o de } \\
\text { playa. }\end{array}$ \\
\hline & Montaña/interior & $\begin{array}{l}\text { Hace referencia a las imágenes donde salen representados elementos } \\
\text { naturales propios de montaña o zonas de interior, como montañas, ríos, } \\
\text { llanuras, bosques, etc. }\end{array}$ \\
\hline & Urbano & $\begin{array}{l}\text { Aglutina imágenes que escenifican un conjunto de elementos urbanos } \\
\text { (casas, calles, plazas...), tanto de grandes ciudades como de pueblos o } \\
\text { municipios pequeños. }\end{array}$ \\
\hline & Parques y jardines & $\begin{array}{l}\text { Incluye aquellas imágenes que escenifican zonas naturales de la } \\
\text { fisonomía de núcleos urbanos. }\end{array}$ \\
\hline \multirow{3}{*}{ Patrimonio } & Monumento & $\begin{array}{l}\text { Construcciones arquitectónicas de grandes dimensiones que, por sus } \\
\text { valores históricos, artísticos y/o culturales, devienen un atractivo } \\
\text { turístico. }\end{array}$ \\
\hline & Conjunto monumental & Conjunto de dos o más elementos patrimoniales. \\
\hline & Artístico & $\begin{array}{l}\text { Incluye todas aquellas representaciones artísticas de pequeñas } \\
\text { dimensiones, como pinturas, frescos, esculturas, murales, etc., así como } \\
\text { fragmentos de grandes atractivos monumentales. }\end{array}$ \\
\hline \multirow[b]{2}{*}{ Cultura } & Fiestas populares & $\begin{array}{l}\text { Hace referencia a los eventos y/o actos que se realizan en motivo de la } \\
\text { celebración de fechas o festividades históricas concretas. }\end{array}$ \\
\hline & Tradiciones culturales & $\begin{array}{l}\text { Incluye aquellas actividades, realizadas por personas locales, que } \\
\text { forman parte de la historia e identidad del territorio, dado que pasan de } \\
\text { generación en generación. }\end{array}$ \\
\hline $\begin{array}{l}\text { Actividades } \\
\text { turísticas }\end{array}$ & & $\begin{array}{l}\text { Se refiere a aquellas actividades turísticas que pueden realizar los } \\
\text { visitantes durante su viaje turístico (actividades deportivas, de compras, } \\
\text { de ocio, etc.). }\end{array}$ \\
\hline
\end{tabular}

Fuente: elaboración propia

Si bien es conocido el uso de software específico para asistir el análisis de contenido, en este caso se ha realizado de forma manual, codificando cada una de las fotografías según los criterios establecidos en una base de datos del programa estadístico SPSS, el cual ha facilitado el posterior análisis de resultados. En particular, los datos obtenidos de la categorización de las fotografías se han analizado mediante tablas de frecuencia y tablas de contingencia.

En cuanto al análisis de contenido de los textos, se ha diferenciado el texto principal del secundario, teniendo en consideración el significado que se quiere transmitir en cada caso. Para su análisis se ha utilizado el método gráfico conocido como wordclouds (nube de palabras), dado que de una forma simple y visual permite detectar cuáles son las palabras más recurrentes. Por último, también se ha tenido en cuenta la localización geográfica a la que hacían referencia los textos. En este sentido, se han realizado representaciones gráficas en un mapa político de Cataluña, indicando cuáles son las comarcas más recurrentes en los carteles motivo de estudio según el nombre del municipio o, en su caso, de la comarca a la que hacía referencia el texto principal. No obstante, en aquellos casos donde este no indica claramente la localización de los carteles, se ha tenido en cuenta el texto secundario. Además, si el texto hace referencia a espacios o zonas naturales que incluyen más de una comarca, tales como Costa Brava, se han tenido en cuenta todas las comarcas 
donde esta zona está incluida, ya que el objetivo es analizar cómo con el texto principal y secundario, el lector es capaz de identificar la imagen del cartel y localizarla en la geografía catalana.

\section{Resultados}

Los carteles analizados se han distribuido, siguiendo la división temporal según las tres etapas del desarrollo del ente de promoción turística de Cataluña: con un 13 \% (25 carteles) en el periodo del DCCT, un $66 \%$ (127 carteles) en el periodo del TC y un $21 \%$ (40 carteles) en el periodo de la ACT.

\subsection{Imagen Turística del destino Cataluña}

En términos globales se puede observar (Tabla 2) que la mayoría de fotografías se concentran en las categorías de "paisaje" y "patrimonio", con porcentajes alrededor del $40 \%$. Si bien, cuando se observan los resultados según periodo se pueden apreciar diferencias significativas que modifican sensiblemente la tendencia general.

Durante el primer período, las imágenes que más repercusión tienen son aquellas referentes a las categorías de "paisaje" y "patrimonio" con una frecuencia relativa del $48 \%$ y $44 \%$, respectivamente. Estas categorías se mantienen como más frecuentes en el siguiente periodo, el de TC; aunque los porcentajes disminuyen ligeramente (29.9\% y $43.3 \%$, respectivamente) a favor de las otras categorías: "cultura" y "actividades turísticas", que ganan relevancia en el conjunto de los carteles analizados.

En el tercer periodo, se observa un cambio en los valores porcentuales de las diferentes categorías. Así pues, el mayor número de carteles editados, una vez constituida la $\mathrm{ACT}$, hace referencia a la categoría de "paisaje" con un 60.5\%, mientras que la categoría de "patrimonio" pierde relevancia a favor de "actividades turísticas", ambas con el mismo valor porcentual (16.3 \%).

Tabla 2. Categorías según periodos de estudio

\begin{tabular}{|l|c|c|c|c|}
\hline Categoría & $\begin{array}{c}\text { DCCT } \\
(1980-1985)\end{array}$ & $\begin{array}{c}\text { TC } \\
(1986-2009)\end{array}$ & $\begin{array}{c}\text { ACT } \\
(2010-2015)\end{array}$ & Total \\
\hline Paisaje & $48 \%$ & $29.9 \%$ & $60.5 \%$ & $39.0 \%$ \\
\hline Patrimonio & $44 \%$ & $43.3 \%$ & $16.3 \%$ & $37.4 \%$ \\
\hline Cultura & $4 \%$ & $15.0 \%$ & $7.0 \%$ & $11.8 \%$ \\
\hline Actividades turísticas & $4 \%$ & $11.8 \%$ & $16.3 \%$ & $11.8 \%$ \\
\hline Total & $100 \%$ & $100 \%$ & $100 \%$ & $100 \%$ \\
\hline
\end{tabular}

Fuente: elaboración propia 
En cuanto a la clasificación de las fotografías según la subcategoría a la que pertenecen, se observan con mayor detalle los elementos que configuran la imagen emitida de Cataluña a través de los carteles. Así pues, en términos generales se observa (Tabla 3) que la subcategoría "artístico" es la que presenta un mayor peso (20\%), seguido de los paisajes de "montaña/interior" (15.9\%), los "monumentos" (14.9\%) y los paisajes de "costa" (12,3\%). Los "parques y jardines" junto a los "conjuntos monumentales" son las subcategorías que presentan una menor representación con un $1.5 \%$ y un $2.6 \%$ respectivamente.

Observando los resultados según períodos, se constata que la imagen paisajística más utilizada en el periodo del DCCT es la de "montaña/interior", con un valor del 20 \%; mientras que, entre las imágenes relacionadas con el patrimonio catalán, el porcentaje se reparte entre las subcategorías "artístico" (24\%) y "monumento" (20\%).

En el segundo periodo, todas las subcategorías muestran valores similares. Sin embargo, aquellos carteles que ponen en valor elementos patrimoniales están clasificados mayoritariamente a la subcategoría "artístico", con un $24.4 \%$. Entre las imágenes culturales, destacan las relacionadas con "fiestas populares", con un $9.4 \%$; seguido de "tradiciones culturales" (5.5\%).

Tabla 3. Subcategoría según periodos de estudio

\begin{tabular}{|c|c|c|c|c|}
\hline & $\begin{array}{c}\text { DCCT } \\
(1980-1985)\end{array}$ & $\begin{array}{c}\text { TC } \\
(1986-2009)\end{array}$ & $\begin{array}{c}\text { ACT } \\
(2010-2015)\end{array}$ & Total \\
\hline \multicolumn{5}{|l|}{ Paisaje } \\
\hline Costa & $16 \%$ & $5.5 \%$ & $30.2 \%$ & $12.3 \%$ \\
\hline Montaña/interior & $20 \%$ & $11.8 \%$ & $25.6 \%$ & $15.9 \%$ \\
\hline Urbano & $8 \%$ & $11 \%$ & $4.7 \%$ & $9.2 \%$ \\
\hline Parques y jardines & $4 \%$ & $1.6 \%$ & - & $1.5 \%$ \\
\hline \multicolumn{5}{|l|}{ Patrimonio } \\
\hline Monumento & $20 \%$ & $16.5 \%$ & $7 \%$ & $14.9 \%$ \\
\hline Conjunto monumental & - & $2.4 \%$ & $4.7 \%$ & $2.6 \%$ \\
\hline Artístico & $24 \%$ & $24.4 \%$ & $4.7 \%$ & $20 \%$ \\
\hline \multicolumn{5}{|l|}{ Cultura } \\
\hline Fiestas populares & $4 \%$ & $9.4 \%$ & $2.3 \%$ & $7.2 \%$ \\
\hline Tradiciones culturales & - & $5.5 \%$ & $4.7 \%$ & $4.6 \%$ \\
\hline Actividades turísticas & $4 \%$ & $11.8 \%$ & $16.3 \%$ & $11.8 \%$ \\
\hline Total & $100 \%$ & $100 \%$ & $100 \%$ & $100 \%$ \\
\hline
\end{tabular}

Fuente: elaboración propia 
En el último periodo definido, se da más importancia a aquellas imágenes que retratan paisajes de "costa" (30.2\%), seguido de los paisajes de "montaña/interior" (25.6\%). Las otras subcategorías se mantienen con unos valores similares, no mostrando tendencias remarcables.

Cabe destacar que la subcategoría "urbano", aunque tienen una baja relevancia en el conjunto de la muestra, representa un $11 \%$ de los carteles editados en el periodo del TC, casi el mismo porcentaje de carteles dedicados a paisajes de "montaña/interior".

\subsection{Grado de humanización de las imágenes}

En el análisis de las fotografías de los carteles se observa una fuerte deshumanización, con una media del 60 \% de las imágenes sin la presencia de ningún individuo. Observando estos resultados por periodos, en la tabla 4 se constata que durante los periodos 1980-1985 y 1986-2009 el grado de deshumanización es mucho mayor que en el último periodo (2010-2015). En el 76 \% de las fotografías del periodo del DCCT no aparece ninguna persona, así como en el periodo del TC dónde se sitúa cerca del $64 \%$. En cambio, esta tendencia está completamente revertida en el último periodo 2010-2015 en el que sólo el 39.5\% de los carteles no hay presencia de personas.

En aquellas imágenes donde aparecen personas, en general, hay más tendencia a mostrar turistas (19\%), tal y como queda demostrado en los periodos del DCCT (16\% de turistas y $4 \%$ de locales) y del TC (20.5\% de turistas y $6.3 \%$ de locales). Sin embargo, en el periodo de la ACT estas categorías se igualan en porcentaje (16.3\%).

Tabla 4. Nivel de humanización según periodo de estudio

\begin{tabular}{|l|c|c|c|c|}
\cline { 2 - 5 } \multicolumn{1}{c|}{} & \begin{tabular}{c} 
DCCT \\
\multicolumn{1}{c|}{}
\end{tabular} & $\begin{array}{c}\text { TC } \\
\text { (1980-1985) }\end{array}$ & $\begin{array}{c}\text { ACT } \\
(1986-2009)\end{array}$ & Total \\
\hline No hay presencia de personas & $76 \%$ & $63.8 \%$ & $39.5 \%$ & $60 \%$ \\
\hline Locales & $4 \%$ & $6.3 \%$ & $16.3 \%$ & $8.2 \%$ \\
\hline Turistas & $16 \%$ & $20.5 \%$ & $16.3 \%$ & $19 \%$ \\
\hline Locales y turistas & $4 \%$ & $9.4 \%$ & $2.3 \%$ & $7.2 \%$ \\
\hline Líderes de opinión & - & - & $25.6 \%$ & $5.6 \%$ \\
\hline Total & $100 \%$ & $100 \%$ & $100 \%$ & $100 \%$ \\
\hline
\end{tabular}

Fuente: elaboración propia

Es importante mencionar que la categoría "líderes de opinión", en referencia a la aparición de personas famosas de reconocimiento nacional $y / 0$ internacional en los carteles, solo tiene representación en el periodo de la ACT, con un valor del $25.6 \%$. Esta característica pone de manifiesto las nuevas tendencias de promoción, basadas en difundir una imagen turística a través de la presencia de personas reconocidas, quienes actúan como prescriptores de la misma.

Otro aspecto analizado en relación al nivel de humanización hace referencia al género de las personas representadas en los carteles, clasificándolos según si hay presencia de hombres, mujeres 
o aparecen ambos. En aquellos casos en que aparecen más de 2 personas se han clasificado los carteles en la categoría de "grupo mixto". También se ha creado un grupo independiente para aquellas ocasiones en la que el género de las personas fotografiadas no se puede identificar, especialmente por la lejanía en la que se ha tomado la fotografía.

Como se puede comprobar en la Tabla 5, los resultados muestran que en la gran mayoría de los carteles donde hay presencia de personas, estas aparecen como un grupo de gente de 3 o más individuos (21.9\%). Por otro lado, los resultados muestran que en aquellos carteles donde aparece una persona, la tendencia es, en todos los periodos, a mostrar hombres. De modo que la representación de mujeres es nula en el periodo del DCCT, de un $0.8 \%$ en el periodo del TC y de un $16.3 \%$ en el periodo de la ACT. Estudios anteriores también han observado esta tendencia. Por ejemplo, Sirakaya y Sonmez (2000) en su estudio sobre el género presente en los folletos turísticos, también observaron una mayor presencia masculina que femenina. Por el contrario, Pécout et al. (2010) concluye en su estudio sobre los carteles de las estaciones balnearias normandas durante el periodo 1880-1960, una clara tendencia a mostrar mujeres, convirtiéndolas en el elemento que encarna el turismo balneario de la época y en su símbolo.

También se debe remarcar el hecho que en los dos primeros periodos la tendencia mayoritaria consiste en mostrar grupos de personas, mientras que en el periodo de la ACT aumenta la presencia de hombres (25.6\%), disminuyendo considerablemente la categoría de grupos mixtos (4.7\%). Por último, aquellos carteles donde hay equidad de género (es decir, aparecen un hombre y una mujer) muestran una evolución positiva a lo largo de los distintos periodos. Mientras que en el primer periodo no hay ningún cartel clasificado en esta categoría, en los periodos del TC y la ACT los porcentajes se sitúan en el $2.4 \%$ y $9.3 \%$, respectivamente. Como último detalle, cabe mencionar el hecho que no se ha podido distinguir claramente el género de un $6.2 \%$ de los carteles, siendo este un porcentaje bastante representativo de las tres etapas.

Tabla 5. Nivel de humanización según periodo de estudio y género

\begin{tabular}{|l|c|c|c|c|}
\cline { 2 - 5 } \multicolumn{1}{c|}{} & \begin{tabular}{c} 
DCCT \\
\multicolumn{1}{c|}{}
\end{tabular} & \begin{tabular}{c} 
TC \\
\multicolumn{1}{c|}{}
\end{tabular} & $\begin{array}{c}\text { ACT } \\
(2010-2015)\end{array}$ & Total \\
\hline No hay presencia de personas & $76 \%$ & $63.8 \%$ & $39.5 \%$ & $60 \%$ \\
\hline Hombre & $4 \%$ & $6.3 \%$ & $25.6 \%$ & $10.2 \%$ \\
\hline Mujer & - & $0.8 \%$ & $16.3 \%$ & $4.1 \%$ \\
\hline Hombre y Mujer & - & $2.4 \%$ & $9.3 \%$ & $3.6 \%$ \\
\hline Grupo mixto (3 o más) & $16 \%$ & $17.7 \%$ & $4.7 \%$ & $21.9 \%$ \\
\hline No se identifica el género & $4 \%$ & $7.1 \%$ & $4.7 \%$ & $6.2 \%$ \\
\hline Total & $100 \%$ & $100 \%$ & $100 \%$ & $100 \%$ \\
\hline
\end{tabular}

Fuente: elaboración propia 


\subsection{Texto principal y secundario de los carteles}

Los resultados muestran que el texto principal que aparece en los carteles turísticos se modifica a lo largo de los tres periodos estudiados (Figura 1). Así pues, en la nube de palabras referente al DCCT, se observa que la tendencia es incluir la palabra "Catalunya" en el texto principal, muy por encima de otros topónimos de carácter comarcal como "Priorat" o "Alt Urgell", o marcas turísticas como "Costa Brava". El único topónimo de carácter local que aparece en este periodo es "Barcelona".

En el segundo periodo (1986-2009), se observa un cambio destacado, dado que el texto principal tiende a indicar el nombre del municipio o comarca dónde se localiza la imagen, por tanto, se apuesta por incluir otros topónimos y marcas turísticas como principal recurso textual. En este sentido, aunque "Catalunya" sigue siendo la palabra más utilizada, topónimos como "Barcelona" y "Val d'Aran" aumentan su representación en el total de los carteles de este periodo, como también lo hace la palabra "Gaudí". En una menor representación aparece el nombre de municipios como "Els Hostalets", "Lloret de Mar", "Tarragona" y "Girona", de marcas turísticas como "Costa Brava" o de fiestas populares como "La Patum".

En el último periodo se observan nuevamente cambios de tendencia. En este caso destaca "Delta de l'Ebre" cómo el texto principal más recurrente, por encima incluso de "Catalunya". Este hecho es debido a la inauguración en Tortosa de la primera Oficina de Turismo de la zona en 2015, hecho que propició la publicación de una colección de carteles referidos a este territorio. En este periodo aparece también con frecuencia el topónimo "Barcelona", y quedan en último lugar las referencias a otros municipios o atractivos turísticos que habían tenido un mayor protagonismo en el periodo anterior.

Cabe destacar también que en algunos casos los carteles de este último periodo destacan como texto principal eslóganes utilizados en distintas campañas de comunicación y que pretenden invitar al individuo a visitar Cataluña, como por ejemplo Sóc FAN de fer història (Soy FAN de hacer historia) o Vine a sopar a casa (Ven a cenar en casa).

\section{Figura 1. Nube de palabras del texto principal}
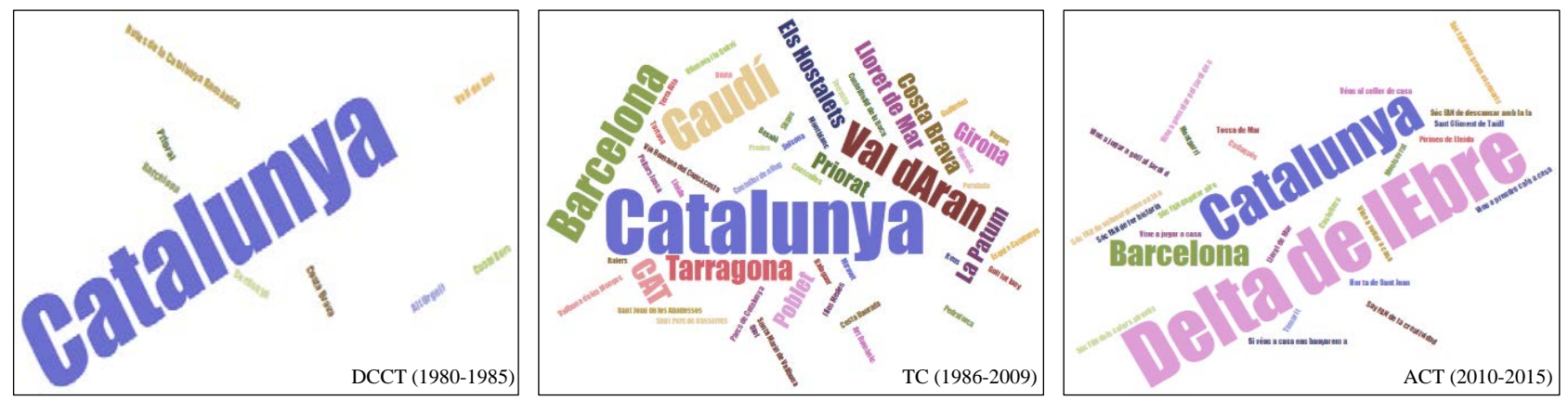

Fuente: elaboración propia 
En referencia al texto secundario (Figura 2), en los tres periodos analizados, en general, este demuestra una estrecha vinculación con el texto principal. Aun así, en el análisis evolutivo del texto secundario se han detectado ciertos cambios de tendencia.

Tal y como se constata en la nube de palabras, durante el primer periodo se hace especial referencia a detalles concretos de la imagen que se retrata en el cartel, como por ejemplo especificando el municipio dónde se encuentra (en caso que el texto principal indique el atractivo) o la comarca (en aquellos casos donde el texto principal indica el municipio). El topónimo "Barcelona" no obstante, es con diferencia la palabra más utilizada en el conjunto de carteles de este periodo, debido a que la mayoría de carteles muestran imágenes de la ciudad de Barcelona.

En el periodo del TC, hay una mayor diversidad de palabras utilizadas como texto secundario, destacando tanto atractivos turísticos como pueblos o comarcas. En este caso, "Catalunya" y "Barcelona" vuelven a ser las palabras más habituales en los carteles, pero seguidas con frecuencias similares por topónimos como "Garrotxa" o "Conca de Barberà".

La principal diferencia con el periodo anterior consiste en un mayor uso de nombres de atractivos turísticos, como por ejemplo "Sagrada Família", "La Pedrera", "Casa Batló", "Passeig Arqueològic" o "Vall de Núria", o nombres de artistas de renombre internacional como "Gaudí", "Picasso" o "Dalí". Mientras que en el periodo anterior se hacía especial referencia a localidades.

\section{Figura 2. Nube de palabras del texto secundario}
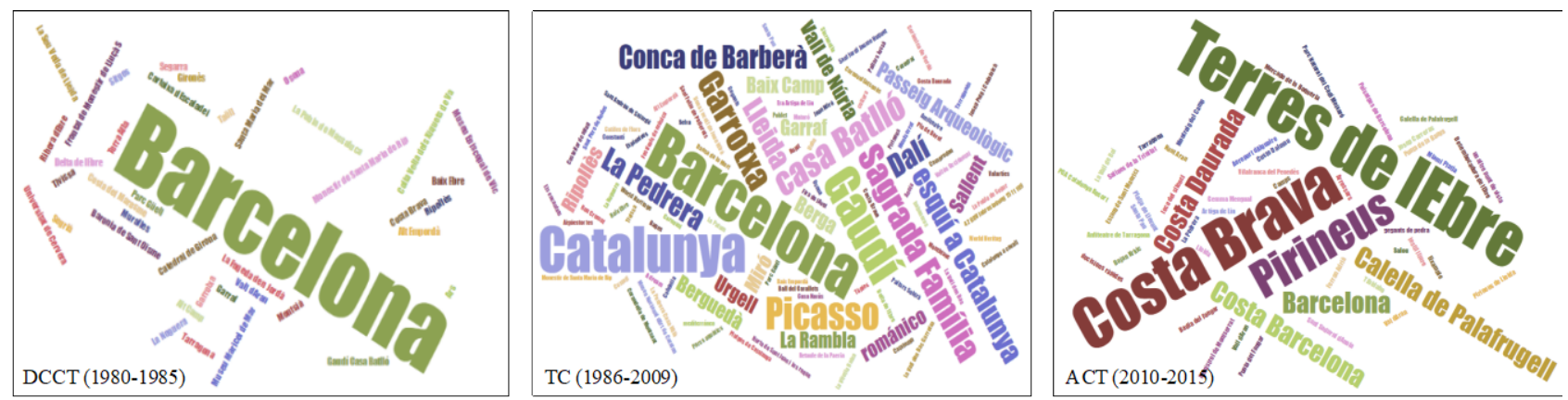

Fuente: elaboración propia

El principal rasgo diferencial del tercer periodo es la baja representación de Barcelona entre los textos secundarios en los carteles editados. Mientras que en los periodos anteriores el nombre de la capital catalana aparecía como el más habitual, en los carteles editados durante la ACT pasa a un nivel minoritario. Además, cabe destacar que entre las palabras más habituales no hay topónimos destacables, sino que aquellos recursos lingüísticos más habituales hacen referencia a marcas turísticas del territorio catalán, como "Terres de l'Ebre", "Costa Brava" y "Pirineus", y con una menor frecuencia otras marcas turísticas como "Costa de Barcelona" y "Costa Daurada". De forma minoritaria también aparecen frases que actúan como soporte al eslogan y/o campaña 
promocional, además de la inclusión del directorio web. Por tanto, se puede concluir que en esta etapa los carteles juegan un papel relevante para la puesta en valor de recursos y espacios situados fuera de la capital catalana.

\subsection{La localización de los carteles}

Dado que en la mayoría de carteles se indica la localización de la imagen, se considera interesante identificar en un mapa político de Cataluña (Figura 3) las regiones con una mayor y menor presencia en los carteles estudiados.

En este sentido, en el mapa que representa el primer periodo (1980-1985), se puede observar como la comarca del Barcelonès es la más habitual en los carteles, puntualizando también que de esta comarca sólo se menciona la ciudad de Barcelona; y en segundo lugar se identifica la comarca del Alt Empordà (7.41\%). De manera general, se observa también que las comarcas más utilizadas en la edición de los carteles de este periodo pertenecen a la provincia de Girona, junto con aquellas de la provincia de Tarragona ubicadas al sur del territorio tarraconense.

En el segundo periodo, el Barcelonès vuelve a ser la comarca más utilizada con un 18.45\% del total de la muestra. Las siguientes comarcas con más carteles editados son la Garrotxa, el Ripollès y el Berguedà, con frecuencias relativas entre el $5.1 \%$ y el $10 \%$. La mayoría de comarcas tienen una representación porcentual de entre $0.1 \%$ y $5 \%$, siendo aquellas localizadas en la costa como, por ejemplo: el Alt Empordà, el Baix Empordà, la Selva, el Tarragonès y el Baix Camp, y aquellas ubicadas en el interior, como Osona, el Bages, el Urgell y la Conca de Barberà.

Cabe destacar que la provincia de Barcelona en su conjunto muestra una mayor representación durante los años incluidos en este periodo, habiendo carteles que retratan elementos de comarcas como el Vallès Occidental, el Maresme y el Baix Llobregat, aunque los valores porcentuales están entre $0.1 \%$ y $5 \%$.

Por último, en un análisis completo de este periodo, se observa un mayor equilibrio en la representación de las cuatro provincias catalanas, teniendo todas un mínimo de carteles editados a lo largo del periodo estudiado. No obstante, también se observa que algunas comarcas no tienen ninguna representación.

En cuanto a los carteles editados durante el período de la ACT, el mapa muestra un cambio de tendencia respecto las comarcas con más representación. Así pues, el Baix Ebre y el Montsià son las comarcas más recurrentes entre los carteles editados a lo largo de este periodo, quitando la hegemonía que hasta entonces tenía la comarca del Barcelonès, la cual se sitúa en las frecuencias relativas de entre $5.1 \%$ y 10 \%, junto con las comarcas de la Vall d'Aran, el Baix Empordà y el Tarragonès. 
Por último, se observa la representación de las comarcas del Pirineu de Lleida en los carteles de este periodo (Alta Ribagorça, Pallars Jussà, Pallars Sobirà, Alt Urgell, Cerdanya, etc.), aunque sea con valores porcentuales bajos (entre el $0.1 \%$ y el $5 \%$ ), tal como sucede en otras comarcas como el Alt Empordà, la Garrotxa, la Selva, el Alt Penedès, el Segrià, el Baix Camp y Terra Alta.

Generalmente, la representación de las diferentes comarcas en el mapa de Cataluña se muestra de manera dispersa, aunque se puede detectar una mayor representación de las comarcas del sur de Cataluña, aquellas que incluyen el Delta de l'Ebre; y de las comarcas del norte, por un lado, las del Pirineu de Lleida; y por el otro lado, aquellas bañadas por la Costa Brava.

\section{Figura 3. Localización de los carteles por comarca}
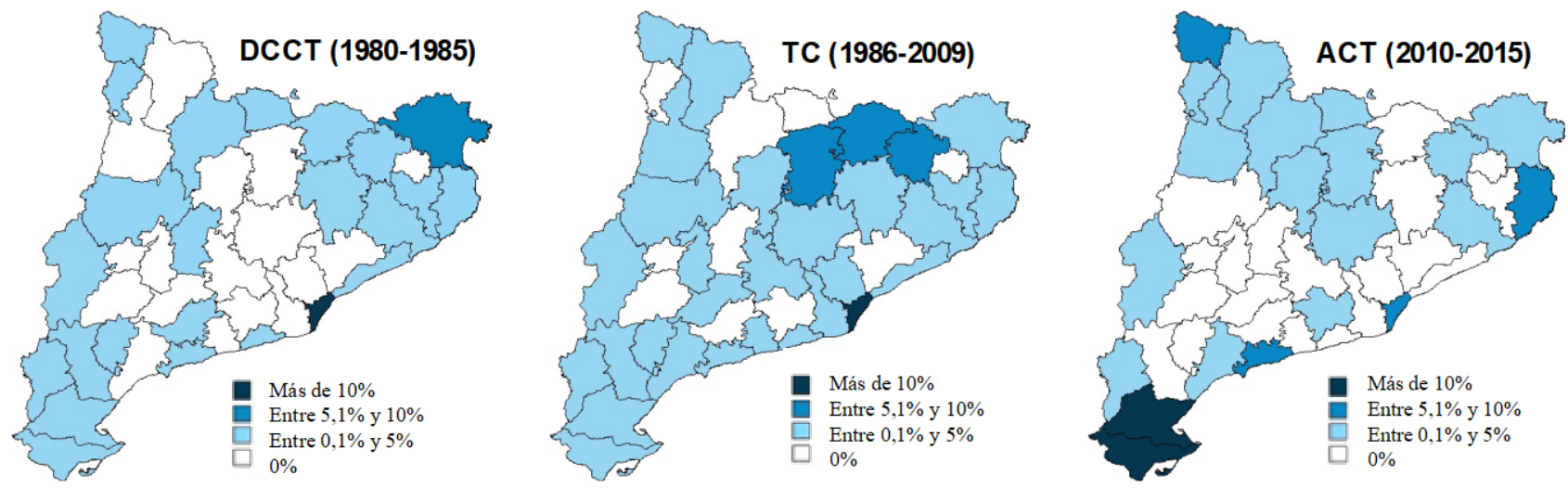

Fuente: elaboración propia

A partir de un análisis comparativo de los tres periodos, se observa que las comarcas incluidas en las marcas Costa Brava, Costa Daurada y Delta de l'Ebre, siempre tienen, con menor o mayor frecuencia, representación en los carteles editados en cada etapa. Por otro lado, la comarca de la Vall d'Aran también muestra una representación constante, juntamente con la comarca de la Garrotxa.

La hegemonía del Barcelonès y, más concretamente, de la ciudad de Barcelona, es clara durante todos los periodos, a excepción del último donde toman el relevo las comarcas del Montsià y el Baix Ebre. Aun así, la presencia de la marca Barcelona, es muy importante durante los 35 años estudiados.

Cabe destacar también, la falta de representación de las comarcas del Pla de l'Estany, el Vallès Oriental, el Pla de l'Urgell y les Garrigues, las cuales no tienen ninguna representación en los carteles turísticos editados a lo largo de los 35 años estudiados. 


\section{Conclusiones}

El presente estudio se ha focalizado en el cartel turístico como herramienta de comunicación y generadora de imagen turística de un destino, tomando como caso de estudio la Comunidad Autónoma de Cataluña.

La relevancia de este estudio está, en primer lugar, en analizar la imagen turística que proyectan los carteles turísticos desde un punto de vista holístico, es decir, no solamente se analiza el contenido de las imágenes, sino que se consideran otros elementos cómo el nivel de humanización de las fotografías o el texto que las acompaña. En segundo lugar, este análisis considera también una perspectiva cronológica, tomando en consideración que la imagen turística promocionada en distintos periodos puede variar substancialmente. Si bien la perspectiva cronológica en el estudio de carteles turísticos se ha realizado con anterioridad de forma frecuente; por lo general, esta se ha limitado a la Belle Epoque hasta los años 30, con alguna excepción. Este artículo va más allá estudiando los carteles turísticos desde los años 80 hasta la actualidad.

Los resultados mostrados en este artículo han sido el resultado de un exhaustivo análisis de contenido. Su validez radica en la utilización de una muestra amplia de carteles (192 carteles) y la categorización de las imágenes mostradas en los mismos, la cual se ha basado en estudios previos (Dilley, 1986; Pritchard \& Morgan, 1995; Jenkins, 2003; Galí \& Donaire, 2005), considerando también los preceptos y recomendaciones de Camprubí y Coromina (2016) para la correcta aplicación del método. En su conjunto, se postula como un estudio que contribuye al conocimiento del cartel turístico como herramienta de promoción, pero también por incorporar nuevas dimensiones metodológicas para el estudio de estas piezas relevantes para la comunicación turística.

En este sentido, los principales resultados obtenidos muestran que las imágenes de los carteles con más repercusión, son aquellas referentes a las categorías de paisaje y patrimonio, sumando entre ambas más del 70 \% del total de la muestra, mientras que la tendencia de los carteles editados es a no mostrar presencia de personas en las imágenes (60\%).

Por otro lado, este análisis ha contemplado el estudio de los carteles turísticos según el periodo en el que fueron editados, teniendo en cuenta que los tres periodos definidos hacen referencia a los distintos entes de promoción que existieron en Cataluña entre los años 1980 y 2015. En este sentido, los resultados obtenidos demuestran la existencia de una estrecha vinculación entre los carteles editados en cada periodo y la imagen turística que se quería transmitir sobre el destino. Los resultados confirman para cada uno de les tres periodos distintas tendencias de promoción. Por lo tanto, se ha confirmado una clara evolución de la imagen turística transmitida a través de los carteles a lo largo de los periodos acotados. 
Con la creación, en 1980, del Departament de Comerç, Consum i Turisme se potenció el paisaje de montaña e interior y el patrimonio monumental y artístico del territorio como elementos principales de la imagen turística de Cataluña. Los carteles editados en este periodo demuestran una clara ausencia de personas en las imágenes, siguiendo así los criterios del viaje romántico donde lo importante es la contemplación del atractivo en solitario y no la realidad social que le rodea (Galí, 2005). Además, se otorga protagonismo a la marca Cataluña, siendo esta el texto principal en la mayoría de los ejemplares.

Durante los años de existencia del Consorci de Turisme de Catalunya, la imagen transmitida seguía los mismos valores elegidos en el período anterior, sin embargo, se demuestra una ligera tendencia a ampliar los recursos y atractivos de Cataluña, transmitiendo otras imágenes, como aquellas relacionadas con el paisaje urbano o con fiestas y tradiciones culturales. En este caso, los carteles demuestran un mayor grado de humanización, potenciando la interacción entre el visitante y el lugar visitado. En este periodo se inicia una mayor presencia de la mujer en el cartel turístico, mayormente acompañada por un hombre o en grupos mixtos. En cuanto a las estrategias de comunicación, se puede observar en los carteles un cambio de tendencia promocional, ya que se apuesta por los nombres de los municipios o los atractivos turísticos como texto principal.

Estos cambios son perceptibles en los carteles editados en los últimos años de este período, sin embargo, es con la puesta en funcionamiento de la Agència Catalana de Turisme en 2010, que se hacen más evidentes. La imagen más presente en los carteles pasa a ser la relacionada con paisajes de costa, aunque aquellos de montaña e interior mantienen un importante reconocimiento. Este hecho se relaciona con la introducción de nuevos territorios no promocionados hasta entonces (p.ej. Alt Urgell o Cerdanya), o bien con una menor incidencia en el periodo anterior (p. ej. Baix Ebre o Montsià). Por otro lado, disminuye la imagen patrimonial y cultural a favor de la imagen que retrata actividades turísticas, mostrando un cambio de tendencia hacia la experimentación del producto turístico del destino. El grado de humanización que demuestran los carteles de este periodo es una de las principales diferencias en comparación con los demás, ya que la mayoría de los carteles incluyen la presencia de personas, además, se apuesta por aquellas con reconocimiento nacional y/o internacional que actúan como prescriptoras de la imagen turística que representan. También se destaca una mayor presencia de la figura femenina y masculina de forma individual. No obstante, continúa siendo la figura masculina la más presente. Entre los elementos textuales, destaca la utilización de textos descriptivos y frases promocionales, así como la apuesta por indicar en los textos la submarca turística a la que pertenece la imagen del cartel. Se observa, por tanto, que la apuesta del nuevo ente de promoción se basa en dar más valor a las submarcas turísticas que hay en el territorio, englobadas bajo la marca paraguas Cataluña.

Como se ha podido observar, bajo la gobernación de un departamento propio de la administración pública autonómica, el principal ente de promoción de Cataluña ha evolucionado a lo largo de los 
años adaptándose a los cambios turísticos que ha experimentado el territorio y, en consecuencia, a las nuevas necesidades y tendencias del mercado. Muestra de ello son las continuas modificaciones que se han hecho en el departamento y los cambios sufridos en la entidad de promoción, tanto de nombre como de forma. ${ }^{1}$ Además, los resultados demuestran una evolución de la imagen, de acuerdo con los nuevos valores turísticos que se ha querido transmitir de Cataluña, propiciada por las diferentes acciones promocionales que se han realizado y que, con esta investigación, se pueden ver reflejadas a través de los carteles turísticos.

Estos resultados se pueden contrastar con los inicios de la restauración de la Generalitat de Catalunya (1977-1980). Tal y como Civit y Boada (2003) apuntan "Una de las primeras e incipientes estrategias de comunicación pública de la Generalitat recuperada consistió en la publicación de los primeros carteles turísticos, los cuales debían satisfacer, sobre todo, dos funciones: retomar la promoción (...) de Cataluña como marca de un destino turístico clara y distinta de la marca España y distinguirse de la línea de comunicación visual marcada por la Secretaría General de Turismo de España (...). Otra función, tácita, era la de contribuir al establecimiento de un código comunicativo propio para la institución recuperada." Así pues, a través del análisis realizado se corrobora que los carteles turísticos editados por las diferentes entidades que han gestionado el turismo en Cataluña en los últimos años, son un recurso fidedigno de los cambios que estas han sufrido y de las nuevas necesidades de promoción que han ido surgiendo, dado que sus modificaciones han influido en la imagen turística del destino.

Por otro lado, el estudio realizado también ha tenido en cuenta el espacio geográfico que se promociona. Se ha constatado que la localización geográfica a la que hacen referencia los carteles también ha variado a lo largo de estos 35 años de estudio. Mientras que el Barcelonès, con Barcelona como máxima exponente, se mantiene en los dos primeros periodos como la comarca con más carteles referenciados a la misma, el Montsià y el Baix Ebre, bajo la denominación Delta de l'Ebre, irrumpen en el tercer periodo con el mayor número de carteles editados. Este hecho, también corroborado en el análisis de los textos y las imágenes donde se observa un aumento de elementos referenciados en las comarcas del sur de Cataluña, es consecuencia de la inauguración en 2015, de la primera oficina de turismo de la marca turística Terres de l'Ebre, situada en Tortosa, por la que, entre diferentes materiales promocionales, se crearon una serie de carteles turísticos destinados a esta submarca territorial, con el objetivo de promocionar el territorio.

Extrapolando este hecho al resto de carteles, encontramos una serie de ejemplares bajo el logotipo de una misma submarca turística, coincidiendo también en diseño, forma y año de edición, que se editaron con motivo de algún acontecimiento concreto, tal y como exponen Civit y Boada (2003)

1 Estas modificaciones están detalladas en diferentes documentos legislativos, como por ejemplo el Decreto 13/1986, el Decreto 40/1990 o el Decreto 83/1997, entre otros. 
"Muchos de estos carteles dedicados a recursos concretos respondían a solicitudes específicas procedentes de municipios o consejos comarcales que habían puesto en marcha campañas o planes de excelencia turística".

Por otra parte, en cuanto al resto de carteles editados, puede parecer que su edición se ha realizado indistintamente, sin embargo, según argumentos de Civit y Boada (2003), la elección de las comarcas o zonas turísticas del territorio representadas en los carteles se ha realizado de acuerdo con criterios promocionales y "alternando paisajes muy característicos del territorio catalán con piezas de primera categoría de nuestro patrimonio monumental y artístico (...) con la voluntad de representar de una manera ecuánime las diversas comarcas".

Aunque desde la entidad responsable de la edición de los carteles se argumenta que los espacios o elementos fotografiados se seleccionan bajo criterios equitativos en todo el territorio y de acuerdo con el patrimonio más relevante del que goza Cataluña, este procedimiento no queda corroborado con los resultados obtenidos. Si bien hay determinados carteles que claramente fueron editados con motivo de algún acontecimiento concreto, para el resto de carteles turísticos, que porcentualmente son mayoritarios, no parece que se sigan criterios concretos para su edición, pues hay atractivos o localidades que sólo tienen una representación en todo el marco temporal estudiado o, incluso, comarcas que no tienen ni una sola representación a lo largo de estos 35 años. Una situación parecida también se desprende del estudio de Fernández y Valero (2015), en la que concluyen un sesgo tanto en la selección territorial como temática. En este contexto, podemos preguntarnos ¿por qué hay espacios invisibles del territorio en los carteles turísticos? ¿cuáles son los criterios utilizados para escoger los recursos y espacios promocionados? La explicación más lógica parecería ser que simplemente hay territorios con un mayor número de atractivos que otros de cara a la demanda, siendo este el criterio utilizado para escoger los espacios geográficos presentes en los carteles turísticos. No obstante, teniendo en cuenta que el ente de promoción debe de actuar globalmente para todo el territorio, también podemos preguntarnos si es necesario el equilibrio promocional de todo el territorio bajo su competencia. Evidentemente, el presente estudio no puede responder a estas preguntas, y seria relevante que en investigaciones futuras se profundizara en esta dirección.

En última instancia, este estudio corrobora el papel de los carteles turísticos en cuanto a exponer los cambios y las adaptaciones que realizan los órganos responsables en materia turística, influenciados por las nuevas líneas estratégicas a las que se quiere apostar. Los carteles han dejado de ser una exposición de los talentos artísticos de sus inicios, para convertirse en una herramienta completamente integrada a los objetivos de la campaña de comunicación del momento. En este sentido, el cartel turístico se ha convertido en una herramienta subsidiaria que complementa las estrategias de la comunicación integrada del marketing, dejando atrás su papel protagonista de antaño. Los resultados del último periodo refuerzan esta idea, considerando el uso de eslóganes e 
imágenes acorde con la campaña de comunicación del momento, y una fuerte presencia de líderes de opinión como prescriptores del destino. La incógnita es saber cómo estos cambios en las estructuras y estrategias de promoción afectarán en el futuro a la edición de los carteles, siendo ya actualmente visible la disminución de esta herramienta de comunicación como recurso promocional, no solo en Cataluña dónde se ha realizado el presente estudio, sino en el mercado turístico en general.

Declaración responsable: Las autoras declaran que no existe ningún conflicto de interés en relación a la publicación de este artículo. Raquel Camprubí ideó el artículo, diseñó la metodología de la investigación, y supervisó el proceso de recogida y análisis de datos. Gemma Descamps fue responsable de la recogida y análisis de datos, así como de la redacción principal del artículo. El texto final fue elaborado en colaboración entre ambas autoras. 


\section{Bibliografía}

Alcocer, J. A. (1991). El mundo del cartel. Madrid: Ediciones Granada.

Baloglu, S., \& Mccleary, K. W. (1999). A model of destination image formation. Annals of Tourism Research, 26, 808-889.

Beerli, A., \& Martin, J. D. (2004). Factors influencing destination image. Annals of Tourism Research, 31(3), 657-681.

Bigné, E., Sánchez, I., \& Sanz, S. (2009). The functional-psychological continuum in the cognitive image of a destination: A confirmatory analysis. Tourism Management, 30, 715-723.

Blanchard, P. (2007). Le Maroc dans I'affiche française (1906-1956). Mélanges de la Casa de Velázquez, 36(1), 131-154.

Camprubí, R., Guia, J., \& Comas, J. (2014). Analyzing image fragmentation in promotional brochures: A case study of two urban destinations. Journal of Hospitality \& Tourism Research, 38(2), 135-161.

Camprubí, R., \& Coromina, L. (2016). Content analysis in tourism research. Tourism Management Perspectives, 18, 134-140.

Centro de Documentación Turística de España. (2005). Catálogo de carteles oficiales de turismo: 1929-1959 (1st ed.). Madrid: Instituto de Estudios Turísticos.

Choi, S., Lehto, X. Y., \& Morrison, A. M. (2007). Destination image representation on the web: Content analysis of Macau travel related websites. Tourism Management, 28(1), 118-129.

Chon, K. S. (1991). Tourism destination image modification process: Marketing implications. Tourism Management, 12(1), 68-72.

Civit, X., \& Boada, M. (2003). Els cartells turístics de la Generalitat recuperada: L'exemple de Girona. In D. Vidal \& O. Monturiol (Eds.), Imatge i Destí: Cartells turístics de les comarques gironines (pp. 47-51). Girona: Museu d'Art.

Coronado, D. (2001). La metáfora del espejo: teoría e historia del cartel publicitario. Sevilla: Alfar. Crompton, J. L. (1979). An assessment of the image of Mexico as a vacation destination and the influence of geographical location upon the image. Journal of Travel Research, 17(4), 18-23.

Debie, F. (1993). Une forme urbaine du premier âge touristique: les promenades littorals. Mappemonde, 1, 32-37.

Dilley, R. S. (1986). Tourist brochures and tourist images. The Canadian Geographer/Le Géographe canadien, 30(1), 59-65. 
Enel, F. (1977). El Cartel: Lenguaje, Funciones, Retórica (2nd ed.). Valencia: Fernando Torres Editor.

Fernández, M. D., \& Valero, J. R. (2015). Carteles, publicidad y territorio: La creación de la identidad turística en España (1929-1936). Cuadernos de Tturismo, 35, 157-184.

Galí, N. (2005). La humanización de las imágenes emitidas por la publicidad de los destinos turísticos monumentales: El caso de Girona. Pasos: Revista de Turismo y Patrimonio Cultural, 3(2), $273-281$.

Galí, N., \& Donaire, J. A. (2005). The social construction of the image of Girona: A methodological approach. Tourism Management, 26(5), 777-785.

Gartner, W. C. (1994). Image Formation Process. Journal of Travel \& Tourism Marketing, 2(2), 191-215.

Gomis, J. (2011). La información turística: Del papel a la red, en Manual de Comunicación Turística: De la información a la persuasión, de la promoción a la emoción (De San Eugenio, J., ed.), Girona: Documenta Universitaria, 29-38.

Govers, R., \& Go, F. M. (2004). Cultural identities constructed, imagined and experienced: A 3gap tourism destination image model. Tourism, 52(2), 165-182.

Guillain, J. (2006). Villégiature, loisirs sportifs et chemins de fer: L'image du sport dans les affiches ferroviaires (1919-1939). Revue d'histoire des chemins de fer, 35, 153-166.

Guillain, J. (2007). Des Territoires Rêvés Aux Espaces D'action. Les Affiches Touristiques à Thème Sportif De L'entre-Deux-Guerres en France (1918-1939). Loisir et Société, 30(1), 43-68.

Gunn, C. A. (1972). Vacationscape: Designing Tourist Regions. University of Texas Press, Austin: Texas.

Jenkins, O. (2003). Photography and travel brochures: The circle of representation. Tourism Geographies, 5(3), 305-328.

Kolbe, R. H., \& Burnett, M. S. (1991). Content-Analysis Research: An examination of applications with directives for improving research reliability and objectivity. The Journal of Consumer Research, 18(2), 243-250.

Kotler, P., Haider, D. H., \& Rein I. (1993). Marketing places: Attracting investment, industry and tourism to cities, states and nations. New York, NY: Free Press.

Laws, E. (1995). Tourism Destination Management: Issues, Analysis and Policies (1st ed.). London: Routledge. 
Monturiol, A. (2011). El cartellisme turístic a Catalunya, dels inicis a la Guerra Civil. Els cartells de I'OTC. In D. Vidal \& A. Monturiol (Eds.), Exposició 75 aniversari de l'Oficina de Turisme de Catalunya (pp. 49-64). Barcelona: Direcció General de Turisme, Departament d'Innovació, Universitats i Empresa de la Generalitat de Catalunya.

Morgan, N., \& Pritchard, A. (1998). Tourism promotion and power: creating images, creating identities (1st ed.). Chichester: John Wiley \& Sons.

Pécout, C., Bohuon, A., \& Birot, L. (2010). La représentation de la femme sur les affiches touristiques balnéaires: Le cas de la Normandie (1880-1960). Revue de recherche en tourisme, Téoros, 29(2), 112-118.

Pégé-Defendi, N. (2003). Une invitation au tourisme: I'affiche ferroviaire française (1880-1936). Revue d'histoire des chemins de fer, 27, 27-38.

Pelta, R. (2011). Visit Spain: The image of Spain in the state's tourist poster (1928-1975). The Poster, 2(2), 109-146.

Pike, S. (2004). Destination Marketing Organisations (1st ed.). Amsterdam: Elsevier.

Pritchard, A., \& Morgan, N. (1995). Evaluating vacation destination brochure images: The case of local authorities in Wales. Journal of Vacation Marketing, 2(1), 23-38.

Pritchard, A., \& Morgan, N. J. (1996). Selling the Celtic arc to the USA: A comparative analysis of the destination brochure images used in the marketing of Ireland, Scotland and Wales. Journal of Vacation Marketing, 2(4), 346-365.

Quendoz, D. (1991). Paysages valaisans pour affiches ferroviaires suisses (des origines à nos jours). In Bulletin annuel de la Bibliothèque et des Archives cantonales du Valais, des Musées de Valère et de la Majorie, Vallesia (pp. 113-124).

Selby, M., \& Morgan, N. J. (1996). Reconstruing a place image: A case study of its role in destination market research. Tourism Management, 17(4), 287-294.

Sirakaya, E., \& Sonmez, S. (2000). Gender images in state tourism brochures: An overlooked area in socially responsible tourism marketing. Journal of Travel Research, 38(4), 353-362.

Suchet, A., \& Tuppen, J. (2009). Rudyard Kipling à Vernet-les-Bains dans le Massif du Canigou. Pyrénées françaises (1910, 1911, 1914 et 1926). Littératures plurielles, Babel, 20, 104-117.

Tasci, A. D. A., Gartner, W., \& Cavusgil, S. T. (2007). Conceptualization and operationalization of destination image. Journal of Hospitality \& Tourism Research, 31, 194-223.

Um, S., \& Crompton, J. L. (1999). The roles of image and perceived constraints at different stages in the tourist's destination decision process. In A. Pizam \& Y. Mansfeld (Eds.), Consumer behavior in travel and Tourism (pp. 81-102). New York: The Haworth Hospitality Press. 
Vidal, D., \& Monturiol, A. (2003). Imatge i Destí: Cartells turístics de les comarques gironines. Girona: Museu d'Art.

Weill, A. (2003). El cartell turístic: Una mirada internacional. In D. Vidal \& A. Monturiol (Eds.), Imatge i Destí: Cartells turístics de les comarques gironines (pp. 19-24). Girona: Museu d'Art.

Young-Hoon, K. (2003). Self-Representation: The Visualization of Koreanness in Tourism Posters during the 1970s and 1980s. Korea Journal, 43(1), 83-105.

Ziolko, C. (2015). Ville, affiche de voyage et imaginaire médiatique 1860-1930. Bulletin du Centre de recherche français à Jérusalem, 26. 